\title{
SCALE-DEPENDENT RECRUITMENT AND DIVERGENCE OF INTERTIDAL COMMUNITIES
}

\author{
Steve Dudgeon ${ }^{1,3}$ And Peter S. Petraitis ${ }^{2}$ \\ ${ }^{1}$ Department of Biology, California State University, Northridge, California 91330-8303 USA \\ ${ }^{2}$ Department of Biology, Leidy Laboratories, University of Pennsylvania, Philadelphia, Pennsylvania 19104-6018 USA
}

\begin{abstract}
Sheltered rocky bays in the Gulf of Maine support communities usually dominated either by the fucoid rockweed Ascophyllum nodosum or the mussel Mytilus edulis. In order to test whether clearing size determines the subsequent pattern of recruitment by intertidal organisms, we examined four common species in clearings in stands of $A$. nodosum. Circular experimental clearings of 1,2, 4, and $8 \mathrm{~m}$ in diameter, which mimicked severe ice scour, and uncleared controls were established at 12 sites spread across four bays. Recruitment of $A$. nodosum and of three species not common in A. nodosum stands (mussels, barnacles, and the rockweed Fucus vesiculosus) varied with clearing size and the patterns did not vary among bays. Recruitment of $A$. nodosum declined exponentially with clearing size. Fucus and barnacles recruited in greater densities to large clearings $(\geq 4 \mathrm{~m})$ compared to small clearings $(<4 \mathrm{~m})$. Recruitment of $F$. vesiculosus was also site specific, reflecting patterns of local abundance, but that of $A$. nodosum was not. Mussels recruited onto artificial substrates in fewer numbers in large clearings, but in marginally greater numbers to rock underneath these substrates in large clearings. Recruitment densities of mussels and barnacles were strongly site specific. These results suggest that (1) the rate of succession varies site specifically, and (2) the trajectory of succession, either convergence toward or divergence from the surrounding community, is contingent upon the interplay between species interactions and the size of the clearing.
\end{abstract}

Key words: alternative states; Ascophyllum nodosum; barnacle; community divergence; Fucus vesiculosus; intertidal communities; Gulf of Maine, USA; mussel; Mytilus edulis; recruitment; rockweeds; scale; Semibalanus balanoides; succession.

\section{INTRODUCTION}

In many ecosystems, the distributions and abundances of organisms carry the signatures of historical events. These events are often unpredictable and vary in their timing and spatial extent (e.g., Levin and Paine 1974, Paine and Levin 1981). This is particularly evident in marine benthic systems where accidental events, such as abrasion of the shoreline by ice, sand, or logs, are common and where the responses by species are scale dependent. For example, patterns of recruitment vary not only with the size of an open patch (e.g., Keough 1984, Sousa 1984, Butler 1991, Kim and DeWreede 1996) but also with the timing and placement of a patch (e.g., Kim and DeWreede 1996, Berlow 1997, Chapman and Underwood 1998). At the very least, the dependence of recruitment on the timing and extent of disturbances can affect the trajectory of succession (Sousa 1984, Pickett and White 1985, Phillips and Shure 1990, Shumway and Bertness 1994).

Whether the outcome of succession in a patch differs from the surrounding community depends on the fate of recruits (Caley et al. 1996). In theory, the final outcome may differ (Lewontin 1969, Sutherland 1974,

Manuscript received 16 November 1998; revised 13 December 1999; accepted 7 February 2000; final version received 22 March 2000.

${ }^{3}$ E-mail: steve.dudgeon@csun.edu
Ricklefs 1987), but much of the experimental evidence suggests that different successional trajectories converge towards the local resident assemblage (Sousa 1984, Berlow 1997, Chapman and Underwood 1998, but see Sutherland 1974, 1981). In other words, history matters early in succession, but ultimately the same community patterns emerge. Yet most of the experimental evidence from marine systems for convergence late in succession derives from small scale experimental clearings (i.e., $<3 \mathrm{~m}^{2}$ ). This is not surprising since in small clearings, convergence would be expected because of edge effects of the surrounding community (Sousa 1984, Petraitis and Dudgeon 1999). The physical and biotic environment of a small patch is likely to be similar to the surrounding undisturbed area.

In contrast, observations of large, naturally formed patches $\left(>30 \mathrm{~m}^{2}\right)$ have yielded more variable outcomes. In some cases assemblages in large clearings converged with the surrounding community albeit more slowly than in small clearings (Paine and Levin 1981, McCook and Chapman 1991, 1993, Tanner et al. 1996, Connell et al. 1997, Minchinton et al. 1997; J. Witman, personal communication), but in others they diverged (Hatcher 1984, Knowlton 1992). These observations suggest that much of the area of a large clearing may lie beyond the edge effects of the surrounding biota that would tend to reestablish the original assemblage (via growth, migration, and local recruitment). Thus, 
recruits in large clearings may have sufficient time and space to become established and develop into a divergent assemblage. Once started, a divergent assemblage may be maintained by positive feedbacks and "ecological engineering" within the community (Peterson 1984, Bertness and Callaway 1994, Jones et al. 1994). Overall, evidence from historical studies (Simenstead et al. 1978), laboratory and microcosm experiments (Drake et al. 1993, Samuels and Drake 1997), and field studies (Sutherland 1974, 1981, Hatcher 1984, Elner and Vadas 1990, Knowlton 1992) suggests that (1) contingency in succession (sensu Berlow 1997) may enable different assemblages to develop, and (2) such succession is scale-dependent (i.e., varies with patch size). Yet few data exist for replicated experiments using large clearings $\left(>10 \mathrm{~m}^{2}\right)$ so these suggested causes for both contingency and scale dependence remain largely unexplored. In this paper, we begin to address these issues by asking if recruitment into large experimental clearings on rocky intertidal shores is strongly scale dependent.

On western north Atlantic shores, ice scour is a common physical disturbance that influences the distribution and abundance of intertidal species. In the Canadian Maritimes and the Saint Lawrence estuary, pack ice forms each year and removes virtually all intertidal organisms living outside cracks and crevices (Bergeron and Bourget 1984). In the southern Gulf of Maine (near Boston, Massachusetts, USA) sea ice has occurred during $\sim 86$ winters in the past $380 \mathrm{yr}$ (Wethey 1985). Wethey's (1985) barnacle study suggests that infrequent, severe ice scour significantly affects species composition for years thereafter. Ice accumulation and scour in the northern Gulf of Maine and off Nova Scotia are intermediate to that of the Maritimes to the north and Boston to the south. Ice accumulates annually in sheltered bays (Mathieson et al. 1982; S. R. Dudgeon and P. S. Petraitis, personal observation) and may remove as much as $50 \%$ of the standing crop of the dominant intertidal seaweed Ascophyllum nodosum (L.) LeJolis (Mathieson et al. 1982). In most years ice does not scrape the surface clean, although this may happen once in $25 \mathrm{yr}$ (Markham 1980, Bedford Institute of Oceanography 1987). Two events, however, stand out. In 1987 , sea ice scoured $>50 \mathrm{~km}$ of shore in Nova Scotia and the damage spanned from the extreme supralittoral to $>1 \mathrm{~m}$ below mean low water (McCook 1992). In the winter of 1978 , extreme cold produced a thick sheet of coastal ice in many areas of the Gulf of Maine. Local fisherman reported the bays on Swan's Island, Maine were completely frozen over and the shoreline scoured by ice. P. S. Petraitis (personal observation) noted extensive scouring in Woods Hole, Massachusetts.

We have hypothesized that large clearings caused by infrequent ice scour coupled with scale-dependent processes during succession may underlie the formation of divergent communities in sheltered bays in the Gulf of Maine. The mid-intertidal zone of sheltered shores is dominated by three distinct assemblages: (1) stands of the canopy-forming fucoid seaweed Ascophyllum nodosum (L.) LeJolis, (2) beds of barnacles (Semibalanus balanoides (L.)) and mussels (Mytilus edulis L.), or rarely (3) the fucoid Fucus vesiculosus L. Rockweed stands (i.e., Ascophyllum or Fucus) and barnacle-mussel beds provide distinct structural habitats (foundation species, sensu Dayton 1972) that harbor different assemblages of species. These assemblages show disjunct distributions, but may occur on adjacent portions of the shore (Lewis 1964), and they typically persist for long periods (mussel beds $>20$ yr, Reynolds 1969; Ascophyllum stands $>100$ yr, Åberg 1992; Fucus stands $>20$ yr, R. L. Vadas, Sr., unpublished data). Post-settlement mortality rates of barnacles and mussels in clearings within Ascophyllum stands are scale dependent. Underneath canopies, or in small clearings, mortality is high because of predation by crabs (Carcinus maenas) and dogwhelks (Nucella lapillus) and sweeping by canopy fronds (Menge 1976, Vadas and Elner 1992, Leonard et al. 1998). In contrast, the rate of predation is lower in large clearings where the edge community has less influence (Petraitis and Dudgeon 1999).

We also suspected that recruitment patterns of barnacles ( $S$. balanoides), rockweeds ( $A$. nodosum and $F$. vesiculosus), and mussels (M. edulis) to clearings within stands of $A$. nodosum were spatial scale dependent and here we report the results of experimental tests of this hypothesis. We expected that germlings of $A$. nodosum would recruit more densely in uncleared areas and small clearings than in large ones because (1) more zygotes settle near parent plants than further away, and (2) post-settlement mortality is extremely high in clearings (S. R. Dudgeon, unpublished data). Algal zygotes in large clearings often die due to desiccation, herbivory, and water motion (Vadas et al. 1990, Brawley and Johnson 1991, Lazo et al. 1994, Cervin and Åberg 1997). In contrast to $A$. nodosum, we expected that barnacles, mussels, and $F$. vesiculosus would recruit more to large clearings within stands of A. nodosum, but not to small clearings or uncleared areas. This prediction stems from greater edge effects of the resident assemblage on settlers in small compared to large clearings. The $A$. nodosum community may adversely affect immigrants in either of two ways: (1) canopy plants impede access of propagules to available space, and (2) early post-settlement mortality of recruits in small clearings is high because of predators harbored by the canopy and dislodgement by the sweeping of fronds.

\section{Materials And Methods}

\section{Study sites}

Research was conducted on Swans Island, Maine $\left(44^{\circ} 10^{\prime} \mathrm{N}, 68^{\circ} 25^{\prime} \mathrm{W}\right)$ in the Gulf of Maine, USA. The island has four distinct bays: Burnt Coat Harbor and 
Toothacher Cove, which face south, and Mackerel Cove, and Seal Cove which face north. The exposure to waves at these sites ranges from extremely protected to moderately protected. The shoreline surfaces at the different sites are a mixture of granite and basalt outcrops, boulder fields, and some muddy patches in the most protected sites.

\section{Experimental design}

The experiment was designed as a stratified randomized block. We established three sites (i.e., blocks) in the mid-intertidal zone $(\sim 0.35-1.0 \mathrm{~m}$ above MLW) in each of the four bays. Sites within each bay were separated by at least $750 \mathrm{~m}$. Prior to clearing, all sites were completely covered by Ascophyllum nodosum. At each site, circular clearings of four different sizes and an uncleared control were made. The sizes of the clearings were $1,2,4$, or $8 \mathrm{~m}$ in diameter, corresponding to 0.79 , $3.14,12.57$, or $50.27 \mathrm{~m}^{2}$ in area. Because of the time required to set up the experiment, clearings were done in two stages. Plots were initially established at all sites between 22 June and 17 August 1996 by removing $A$. nodosum and marking the center of each clearing with stainless steel screws in plastic anchors inserted in holes drilled in the rock. To represent an ice scour event during winter all plots were completely scraped using paint scrapers between 6 and 10 February 1997 and thereafter left unmanipulated. In order to mimic a severe ice scour, we scraped the substrate of plots until all organisms on flat surfaces were removed. Thus, holdfasts of $A$. nodosum on flat surfaces were scraped down to the rock surface leaving perhaps a few layers of cells in pits in the rock. Organisms in narrow and deep (more than $\sim 1 \mathrm{~cm}$ ) cracks and crevices (gastropods, a few barnacles and mussels, crabs, small algae) were left intact. Holdfasts of $A$. nodosum anchored $>1$ $\mathrm{cm}$ deep in these crevices were also left intact, but fronds of these thalli were cut off at the height at which they emerged from the crack (typically $<5 \mathrm{~cm}$ ). This treatment effectively precludes patch closure by vegetative growth because $A$. nodosum does not regenerate from holdfasts (S. R. Dudgeon, personal observation). Moreover, regeneration from frond lengths $<10 \mathrm{~cm}$ is extremely slow (R. L. Vadas, Sr., personal communication), and individuals in cracks often died from exposure during the summer of 1997 (S. R. Dudgeon, personal observation). Recolonization of these clearings by $A$. nodosum would occur via recruitment of zygotes.

In late winter and spring, substrates for recruitment of barnacles (Semibalanus balanoides), rockweeds ( $A$. nodosum), and mussels (Mytilus edulis) were secured to the rock with a screw in the center of each clearing (i.e., at the corners of a centrally placed $30 \times 30 \mathrm{~cm}$ quadrat) and under the Ascophyllum canopy in control plots during the period of recruitment for each species.

Barnacle recruitment.-In Maine, barnacle cyprid larvae begin to settle in March and continue through
May (S. R. Dudgeon and P. S. Petraitis, personal observation). Substrates for recruitment of Semibalanus balanoides were set out between 8 and 10 March 1997 and collected between 10 and 12 May 1997, a period of $63 \mathrm{~d}$. We checked these surfaces at $3 \mathrm{wk}$ intervals during March and April to determine the onset of recruitment. These substrates were fiberglass resin (Evercoat Fiberglass Resin, Cincinnatti, Ohio, USA) castings made from latex molds imprinted with a natural granite rock surface. The resin plates were $\sim 0.67 \mathrm{~cm}$ thick discs that were $7.1 \mathrm{~cm}$ in diameter $\left(39.6 \mathrm{~cm}^{2}\right.$ area) with a screw hole in the center. We used five different molds having similar topographies. The different plate topographies were set out such that each plate type was used once within a site. Across all four bays each plate topography was replicated either two or three times in each different size clearing.

Following collection, the number of cyprid larvae and metamorphosed barnacle spat were counted on each plate under a dissecting microscope at $25 \times$. The sum of metamorphosed spat and cyprid larvae was used for data analysis.

Recruitment of rockweeds: Ascophyllum and $\mathrm{Fu}-$ cus.-The reproductive season of $A$. nodosum in eastern Maine near Swan's Island spans a 3-7-wk period in spring (Bacon and Vadas 1991). Gametes are released at ebb tide, especially on warm sunny days that rapidly dry the receptacles in which the gametes are stored, and are washed from the receptacles by the incoming tide (Vadas et al. 1990). F. vesiculosus was rare near most of our experimental plots, but was patchily abundant in the surrounding area at three sites, Ledges, July 4, and Dick's. F. vesiculosus in eastern Maine starts reproducing in late April and May, peaks between May and July, but remains reproductive until October except for a short break in late July and August (R. L. Vadas, Sr., personal communication). For both species, we sought to estimate recruitment as soon after the peak settlement season to minimize post-recruitment mortality (see Caley et al. 1996 for the importance of doing so). This resulted in different sampling methods being most suitable for these two species.

We counted recruits of $F$. vesiculosus in August 1997 following the peak period of recruitment. Since Fucus germlings in the field grow rapidly, recruits were visible on the rock surface of the clearing by August, and identification as Fucus was unambiguous. We estimated $F$. vesiculosus recruitment from the average of counts in five $0.25-\mathrm{m}^{2}$ quadrats that were placed haphazardly in each clearing except the 1-m clearings. Given the small areal extent of the 1-m clearings, there was the potential for the five quadrats to be resamples for the same area. In order to minimize resampling the same plants, four quadrats were set so they did not overlap, and the fifth quadrat was tossed haphazardly into the clearing. Haphazard tosses of quadrats in the larger clearings could potentially resample the same plants, but because of the larger areas of these plots 
were less likely to do so. The difference in sampling between $1 \mathrm{~m}$ and other clearing sizes affects the estimate of the variance for the five quadrats but has no systematic bias on the estimate of the mean, which we used as our estimate of Fucus recruitment. The average number of recruits per $0.25 \mathrm{~m}^{2}$ was used for data analysis.

Artificial substrates for recruitment of A. nodosum embryos and very young germlings were set out on 67 April 1997 and collected between 26 and 28 May 1997, $\sim 50 \mathrm{~d}$, which encompassed the entire reproductive season of A. nodosum on Swans Island (S. R. Dudgeon, personal observation). In contrast to Fucus, A. nodosum germlings grow slowly (S. R. Dudgeon, personal observation), so substrates that could be collected and viewed under a microscope were necessary for estimating recruitment immediately following the reproductive season. The substrates were $5 \times 5 \times 1 \mathrm{~cm}$ white ceramic tiles with a screw hole in the center (see Vadas et al. 1990 for a complete description of a similar tile and clay composition). The white surface provided a reflective rather than a heat-absorbing surface. The tiles were imprinted with a very fine grain sand paper (number 80 ) to simulate the pits of natural surfaces that provide refuges for zygotes and germlings. Prior to firing a grid was also imprinted on the tile dividing the surface into $0.5 \times 0.5 \mathrm{~cm}$ squares. Therefore, in addition to the textured square surfaces, the grooves between squares also provided settlement sites for zygotes and germlings.

The average number of germlings per square or groove based on counts of five of each selected at random for each tile was used for data analysis. Embryos and very young germlings of A. nodosum and Fucus spp. look similar until those of Fucus begin to flatten in cross section, but can be distinguished by the presence of apical hairs in Fucus and their absence in A. nodosum germlings $<2$ mo old (Fritsch 1945; S. R. Dudgeon, personal observation). We did not observe apical hairs on germlings indicating that those on the tiles were those of A. nodosum. Resolving the presence or absence of apical hairs on germlings from fieldcollected samples is occasionally difficult, so we also compared for each experimental plot the density of germlings on the tile with the number of known recruits of Fucus from the counts made in the summer of 1997 (see Results).

Mussel recruitment.-In Maine, mussels begin to settle in June and continue through September (Bethel 1973, Petraitis 1991). Substrates for recruitment of $M y$ tilus edulis were set out on 2-3 June 1997 and collected between 8 and 10 August for a period of $\sim 68 \mathrm{~d}$. We periodically checked these substrates (every 2 wk) during June and July to determine the onset of mussel recruitment. We used $\sim 40 \mathrm{~cm}^{2}$ rectangular pieces cut from furnace filters (Purolator Air Filtration Products, Brentwood, Tennessee, USA) that consisted of a mesh backing and a fibrous matrix as a substrate for mussel recruitment. Since some pads eroded during the 68-d period we determined pad size (by mass and area) after collection. Upon collection of the pads, mussel recruits ( $\sim 500 \mu \mathrm{m}$ in length) remaining on the rock surface underneath the pad were counted with a hand lens, the extent of sedimentation was assessed by assigning a rank, and the areal coverage of the rock by the pad determined by counting the number of $1-\mathrm{cm}$ squares that comprised the pad. Sediment loads were ranked for each plot using the following ordinal scale: 1 , no sediment; 2, light sand; 3, moderate sand; 4, heavy sand; 5 , mud; and 6 , extremely muddy/silty. Pads with mussels were placed in plastic bags and preserved in $70 \%$ isopropyl alcohol within $2 \mathrm{~h}$ of collection. To sort mussels from the pads for counting, the pads were thoroughly rinsed with water over a series of three sieves: $1 \mathrm{~mm}, 425 \mu \mathrm{m}$, and $300 \mu \mathrm{m}$ mesh. Mussels trapped on the $425-\mu \mathrm{m}$ and $300-\mu \mathrm{m}$ mesh sieves were placed in separate petri dishes and dispersed in water prior to counting. The number of mussels in 10 haphazardly chosen $10 \mathrm{~mm}$ diameter dissecting microscope fields in each dish were counted. The 10 fields counted comprised $12.3 \%$ of the total area of a petri dish $(90 \mathrm{~mm}$ diameter) and, thus, constituted $12.3 \%$ of the sample in each sieve. Pads were dried for $48-72 \mathrm{~h}$ at $25^{\circ} \mathrm{C}$ to determine their mass.

Counts of mussel recruits remaining on the rock were expressed on a per pad area basis, and counts of those in the pad were expressed as per gram mass of pad. Analyses of recruits in the pad for each size class were done on the summed number of mussels across the 10 fields.

We paired 18 pads with 18 fiberglass resin plate castings of barnacles. Resin plates of barnacles were used by Petraitis (1991) to estimate mussel recruitment. Pairs were placed at two of the sites in Toothacher Cove and Mackerel Cove used in Petraitis (1991) to determine if mussels recruited similarly to pads and casts of barnacle surfaces. These data enable comparison of recruitment in the present study with earlier data $(\mathrm{Pe}-$ traitis 1991).

\section{Statistical analyses of data}

Mussel data were $\log _{10}(1+x)$ transformed, and data for all other species were square root $(x+0.5)$ transformed to homogenize variances. Data presented in figures represent the back-transformed means and 95\% confidence limits (Sokal and Rohlf 1995). Data were analyzed using three-factor analyses of variance (ANOVA) with size of clearing crossed with bays and with sites nested within bays. Clearing size was considered a fixed factor and bays and sites within bays were considered random effects. The mean square for clearing size was tested over the bay $\times$ size interaction mean square, and the mean square for the effect of bays was tested over the sites within bays mean square. Synthetic mean squares were used to form the appropriate $F$ ratios in cases where missing data made the design unbal- 
anced. In testing the effect of clearing size, four preplanned single degree of freedom contrasts were used: (1) uncleared ( $0 \mathrm{~m}$ diameter clearing) vs. all cleared plots, (2) 0 - and 1-m clearings vs. 2-, 4-, and 8-m clearings, (3) 0-, 1-, and 2-m clearings vs. 4- and 8-m clearings, and (4) 0-, 1-, 2-, and 4-m clearings vs. 8$\mathrm{m}$ clearings. Each comparison tests for differences between two subgroupings of the treatments (e.g., the overall average of $0-, 1-$, and $2-m$ clearings vs. the overall average of 4- and 8-m clearings) and allow us to detect breakpoints (i.e., thresholds) in the data. Alpha values for the planned contrasts were adjusted using the Bonferroni correction (adjusted $\alpha=0.05 / 4=$ $0.0125)$. A single degree of freedom contrast was used to test for the effect of north- vs. south-facing bays on the density of recruitment.

Variance components for the effects of bays, sites within bays, bay $\times$ size interaction, and the residual error were calculated using the restricted maximum likelihood method (see VARCOMP procedure in SAS Institute 1989).

Ad hoc tests of power to detect differences in recruitment were based on assumed minimum biologically significant effect sizes and the residual variability in recruitment for each species. Assumed significant effect sizes were set prior to the experiment, but analyses were done retrospectively since they relied upon residuals from the experimental data. In the case of clearing size, we assumed an effect size of 1 recruit per $4 \mathrm{~cm}^{2}$ (2500 individuals $/ \mathrm{m}^{2}$ ) was a significant gradient, and in the case of the random effects (bay, site(bay), bay $\times$ size, barnacle plate, plate $\times$ size), we assumed that variance components that comprised at least $15 \%$ of the total variance were also meaningful. The power of the experiment to resolve 1 recruit per $4 \mathrm{~cm}^{2}$ among clearing sizes for each species were as follows: barnacles, 0.18; Ascophyllum (on flat surfaces), 0.93; Ascophyllum (in grooves), 0.46; Fucus, 0.24; mussels (on rock), 0.70; mussels (in pads), 0.34. The power of the preplanned contrasts were slightly greater ranging from 0.18 (for barnacles) to 0.98 (for Ascophyllum on flat surfaces). The power of the experiment to detect significant variation among bays, sites within bays, the bay $\times$ size interaction, plate, and the plate $\times$ size interaction was $0.35,0.29,0.21,0.13$, and 0.07 , respectively. In accord with Peterman (1990), we consider tests of hypotheses in which the power was $<0.80$ to be weak tests and those in which power exceeds 0.80 to be strong tests. Thus, all tests of random effects were weak, and only the test of Ascophyllum recruitment onto flat surfaces with respect to clearing size was strong.

For mussel recruitment, we tested whether the accumulation of sediment on the substrate underneath the pad was inversely correlated with (1) clearing size and (2) mussel recruitment. This may be expected because pads may accumulate more sediment in habitats within canopies or small clearings where water movement may be lower and, hence, adversely affect mussel recruitment. Nonparametric correlation analyses using Kendall's $\tau$ tested the concordance between the sediment load ranking of each plot and either clearing size or mussel recruitment (for both size classes and those on rock).

\section{REsUlts}

\section{Barnacle recruitment}

Few barnacle cyprid larvae and no metamorphosed barnacle spat were observed in early April. Most settlement onto plates occurred between mid-April and mid-May 1997. We did not detect any differences in recruitment of barnacles to the five different resin plate topographies $\left(F_{\text {plate }}=1.83, \mathrm{df}=4,9, P=0.21, \mathrm{SE}=\right.$ 8.89 ), nor were there differences in recruitment to a given plate topography in the differently sized experimental clearings $\left(F_{\text {plate } \times \text { size }}=0.51, \mathrm{df}=15,24, P=\right.$ 0.91, $\mathrm{SE}=19.96)$.

Barnacles recruited in greater numbers to large clearings compared to small clearings, and this pattern was consistent across all four bays (Table 1). Barnacles recruited in the fewest numbers to uncleared control plots. Four preplanned contrasts showed that the number of recruits increased as a function of clearing size up to $4 \mathrm{~m}$ in diameter (Table 1, Fig. 1). No further increase in the abundance of recruits occurred in $8 \mathrm{~m}$ diameter clearings compared to that of clearings $4 \mathrm{~m}$ in diameter.

No differences in barnacle recruitment were observed among the four bays (Table 1). Although the south-facing bays tended to have greater recruitment than the north-facing bays, this difference was not significant (Table 1).

The recruitment of barnacles also varied among sites within each bay (Table 1). Sites within bays accounted for $27 \%$ of the total variance in barnacle recruitment. In each of the two north-facing bays (Mackerel Cove and Seal Cove), fewer barnacles tended to recruit to the sites furthest back in the bay (Grace and Pole 24, respectively; Fig. 2). However, this trend was not apparent in the two south-facing bays, Toothacher Cove and Burnt Coat Harbor. In Toothacher Cove, the recruitment of barnacles was lower at the outermost site (Ledges) in the bay.

\section{Recruitment of rockweeds: Ascophyllum and Fucus}

A. nodosum and $F$. vesiculosus showed virtually no spatial overlap in recruitment. Plots that had $A$. nodosum germlings in May had little or no Fucus in August. More importantly, plots with Fucus present in August had few, if any, A. nodosum germlings on the tiles in May, confirming that germlings on tiles were those of A. nodosum (Fig. 3).

For A. nodosum, the patterns of recruitment by germlings on flats and in grooves of the tiles were nearly identical, except that densities in grooves were 
TABLE 1. Summary of analyses of variance of barnacle, rockweed, and mussel recruitment in the Gulf of Maine based on experimental design described in Materials and Methods.

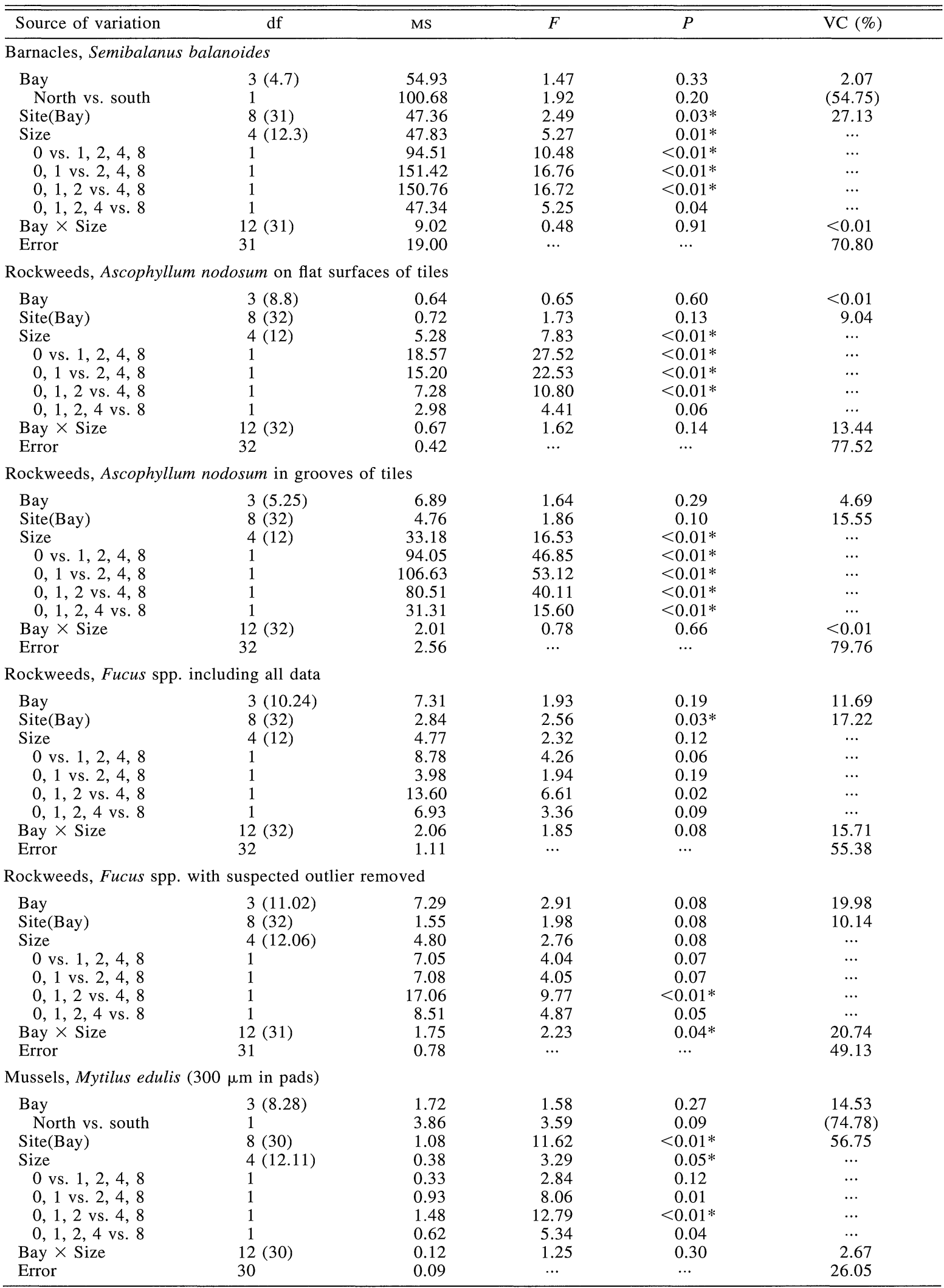


TABle 1. Continued.

\begin{tabular}{|c|c|c|c|c|c|}
\hline Source of variation & df & MS & $F$ & $P$ & $\mathrm{VC}(\%)$ \\
\hline \multicolumn{6}{|c|}{ Mussels, Mytilus edulis (425 $\mu \mathrm{m}$ in pads) } \\
\hline $\begin{array}{l}\text { Bay } \\
\quad \text { North vs. south } \\
\text { Site(Bay) } \\
\text { Size } \\
0 \text { vs. } 1,2,4,8 \\
0,1 \text { vs. } 2,4,8 \\
0,1,2 \text { vs. } 4,8 \\
0,1,2,4 \text { vs. } 8 \\
\text { Bay } \times \text { Size } \\
\text { Error }\end{array}$ & $\begin{array}{l}3(7.63) \\
1 \\
8(30) \\
4(12.17) \\
1 \\
1 \\
1 \\
1 \\
12(30) \\
30\end{array}$ & $\begin{array}{l}1.15 \\
2.42 \\
0.70 \\
0.23 \\
0.16 \\
0.73 \\
0.65 \\
0.40 \\
0.07 \\
0.08\end{array}$ & $\begin{array}{r}1.67 \\
3.44 \\
8.65 \\
3.32 \\
2.34 \\
10.80 \\
9.66 \\
5.89 \\
0.83 \\
\cdots\end{array}$ & $\begin{array}{c}0.25 \\
0.10 \\
<0.01^{*} \\
0.05^{*} \\
0.15 \\
<0.01^{*} \\
<0.01^{*} \\
0.03 \\
0.62 \\
\ldots\end{array}$ & $\begin{array}{c}14.46 \\
(70.43) \\
53.21 \\
\ldots \\
\ldots \\
\ldots \\
\ldots \\
\ldots \\
<0.01 \\
32.33\end{array}$ \\
\hline \multicolumn{6}{|c|}{ Mussels, Mytilus edulis (on rock underneath pads) } \\
\hline $\begin{array}{l}\text { Bay } \\
\text { North vs. south } \\
\text { Site(Bay) } \\
\text { Size } \\
0 \text { vs. } 1,2,4,8 \\
0,1 \text { vs. } 2,4,8 \\
0,1,2 \text { vs. } 4,8 \\
0,1,2,4 \text { vs. } 8 \\
\text { Bay } \times \text { Size } \\
\text { Error }\end{array}$ & $\begin{array}{l}3(9.53) \\
1 \\
8(32) \\
4(12) \\
1 \\
1 \\
1 \\
1 \\
12(32) \\
32\end{array}$ & $\begin{array}{l}0.07 \\
0.06 \\
0.05 \\
0.04 \\
0.06 \\
0.05 \\
0.13 \\
0.04 \\
0.02 \\
0.01\end{array}$ & $\begin{array}{l}1.27 \\
1.25 \\
5.20 \\
2.20 \\
3.45 \\
2.96 \\
7.72 \\
2.56 \\
1.70\end{array}$ & $\begin{array}{c}0.34 \\
0.30 \\
<0.01 * \\
0.13 \\
0.09 \\
0.11 \\
0.02 \\
0.14 \\
0.11\end{array}$ & $\begin{array}{c}4.86 \\
(28.98) \\
38.56 \\
\ldots \\
\ldots \\
\cdots \\
\cdots \\
\ldots \\
10.72 \\
45.86\end{array}$ \\
\hline
\end{tabular}

Notes: Data were square root $(+0.5)$ transformed, except mussel data which were $\log _{10}(1+x)$ transformed. Denominator degrees of freedom based on the synthetic mean squares for each source of variation are included in parentheses next to the numerator df. Preplanned contrasts are included as rows immediately following the class variable to which they correspond. VC refers to the percentage of the total variance due to each random component of the model. Percentages in parentheses indicate the percentage of the total variance for bays explained by recruitment in north- vs. south-facing bays.

* Significant sources of variation.

much greater than those on flats (Fig. 4). Early postsettlement recruitment of $A$. nodosum varied only with respect to clearing size and this pattern was invariant across all bays (Table 1). Germling densities in both grooves and flats were greatest in the uncleared control plots and declined exponentially with increased clearing size (Fig. 4).

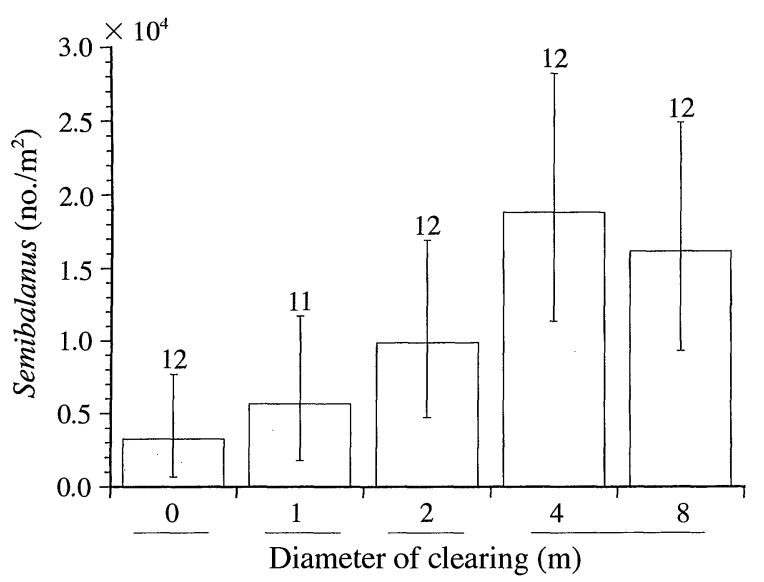

FIG. 1. Recruitment density of barnacles (Semibalanus balanoides) in the differently sized experimental clearings in the Gulf of Maine. Data represent back-transformed means and $95 \%$ confidence intervals. Numbers above each column represent sample sizes. Breaks in the line under treatment levels indicate where significant step thresholds in recruitment occurred (based on planned contrasts at $\alpha=0.0125$ ).
For $F$. vesiculosus, recruitment also varied with clearing size (Table 1) but the pattern was in the opposite direction to that of $A$. nodosum (Fig. 5). A single step threshold occurred between the 2 and 4 m diameter clearings with densities being greatest in the 4 and 8 $\mathrm{m}$ diameter clearings and less in smaller clearings (Table 1). Uncleared control plots had the fewest number of $F$. vesiculosus recruits. In Fig. 5 only 11 observations are shown for the 1-m clearing size because of a probable outlier at one site. At the 1-m clearing at one site in Burnt Coat Harbor several plants of $F$. vesiculosus were observed near the clearing, and recruitment of Fucus in this plot was anomalously high. A comparison of the variance components for the analyses of variance of Fucus recruitment with and without this observation are consistent with the interpretation of this observation as an outlier. The percentage of the total variance due to the error term of the model declined by $6.25 \%$ by excluding this single observation from the data set (Table 1). Moreover, excluding this observation clearly distinguished a threshold pattern of similar densities of Fucus recruitment in $0-, 1$-, and 2m clearings (back-transformed mean + upper $95 \% \mathrm{CI}$; $0.89+7.15,4.86+12.184,2.68+9.26$ individuals $/$ $\mathrm{m}^{2}$ for $0-, 1-$, and $2-\mathrm{m}$ clearings, respectively) and greater densities in 4- and 8-m clearings (mean - lower $95 \% \mathrm{cI} ; 14.91-10.64,18.81-12.27$ individuals $/ \mathrm{m}^{2}$ for 4- and 8-m clearings, respectively).

The pattern of Fucus recruitment in clearings of different sizes varied slightly among the four bays (Table 

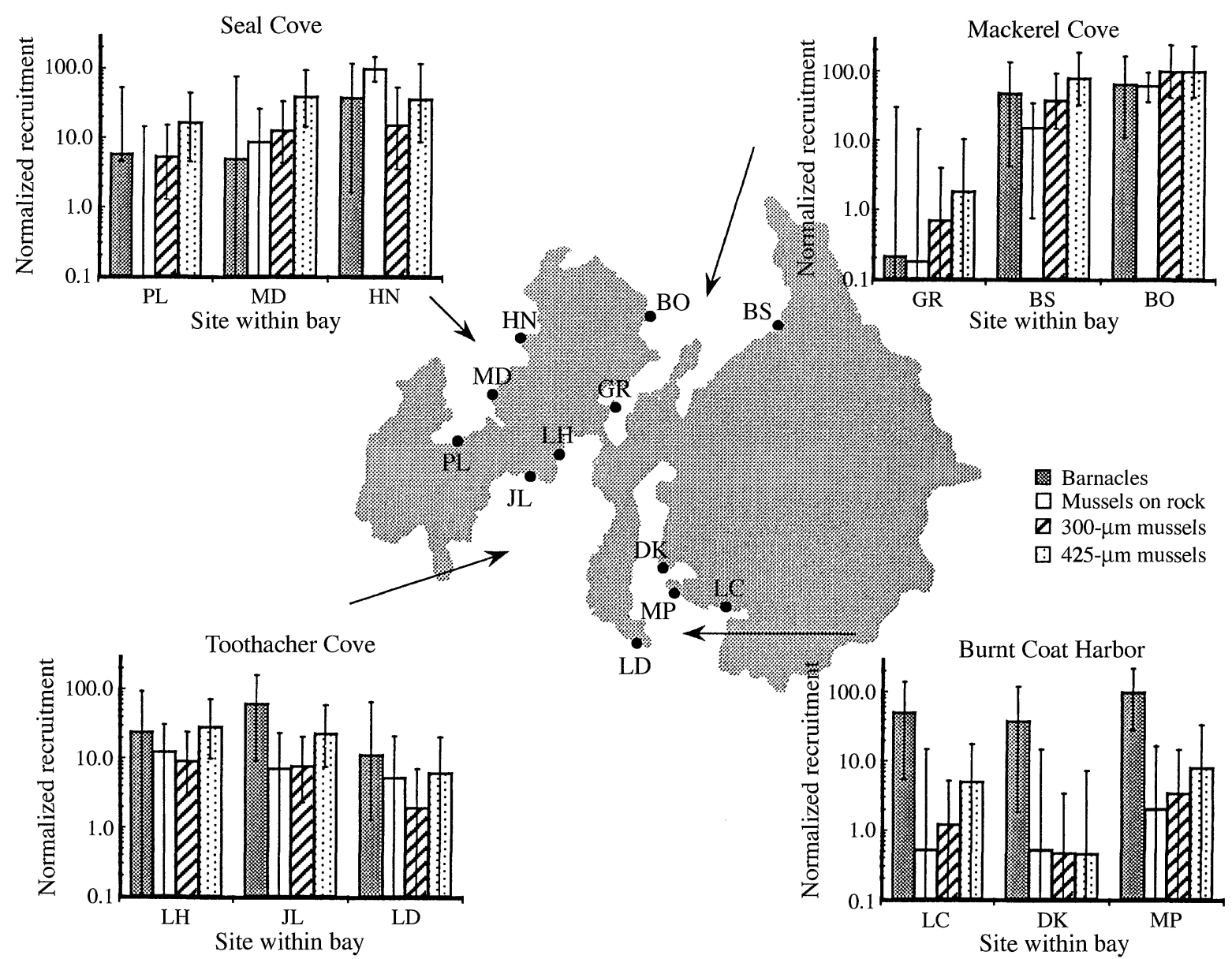

Site within bay

FIG. 2. Location-specific recruitment patterns of barnacles, mussels on rock underneath pads, 300-425- $\mu$ m mussels, and $>425-\mu \mathrm{m}$ mussels in pads. Recruitment densities for each group are based on back-transformed means that were normalized with respect to the site having the highest density and are expressed as percentages. Maximum site-specific recruitment density (i.e., $100 \%$ ) was 3.33 individuals $/ \mathrm{cm}^{2}$ for barnacles, 2.27 individuals $/ \mathrm{cm}^{2}$ for mussels underneath pads, 60.99 individuals/g pad for 300- $\mu \mathrm{m}$ mussels and 20.34 individuals/g pad for $425-\mu \mathrm{m}$ mussels. Bars represent normalized averages and 95\% confidence intervals of $N=5$ observations per site (except for barnacles at middle site in Seal Cove and 300- and 425$\mu \mathrm{m}$ mussels at outer sites in Seal Cove and Burnt Coat Harbor where $N=4$ ). Arrows identify the bay to which the plot refers, and symbols on the map identify the sites: BO, Bob's; BS, Basil; GR, Grace; LC, Long Cove; MP, Mill Pond; DK, Dick's; LD, Ledges; JL, July 4; LH, Little House Cove; PL, Pole 24; MD, MacDuffie; HN, Hen Island.

1 , bay $\times$ size interaction analysis with outlier removed). This was driven by greater variability in recruitment among the clearings in Toothacher Cove than in the other bays. Nevertheless, in each bay recruitment tended to be greater in the larger clearings.

As well as the effect of clearing size, recruitment of $F$. vesiculosus also varied among sites within bays (Table 1, analysis of all data). However, the analysis is sensitive to the presence of the outlier suggesting the variation among sites within bays is marginal.

\section{Mussel recruitment}

We did not observe mussel recruits during June 1997; most of the recruitment occurred in July and August 1997. The recruitment of mussels differed among clearings, but the pattern of variation with clearing size varied between recruits in the pad and those observed on rock underneath the pad (Table 1). Both the 300and $425-\mu \mathrm{m}$ mussels that recruited in pads were more abundant in smaller ( $\leq 2 \mathrm{~m}$ in diameter) than in the larger clearings (Fig. 6A). Both size classes showed a two-step pattern with the first step down occurring between the 1 and $2 \mathrm{~m}$ diameter clearings and the second step between 2 and $4 \mathrm{~m}$ diameter clearings (Table 1). The $P$ value of the former contrast for the $300-\mu \mathrm{m}$ mussels was marginally nonsignificant, but the power was weak. The similar patterns of recruitment by the two size classes of mussels in the pads drove the overall pattern of mussel recruitment. Mussels recruited underneath pads in greater numbers in the large (4 and 8 $\mathrm{m}$ diameter, 294 and 382 individuals $/ \mathrm{m}^{2}$, respectively) than in the small $(0,1$, and $2 \mathrm{~m}$ diameter, 20, 48, and 11 individuals $/ \mathrm{m}^{2}$, respectively) clearings (Fig. 6B). The $P$ value $(P=0.016)$, however, for this contrast 


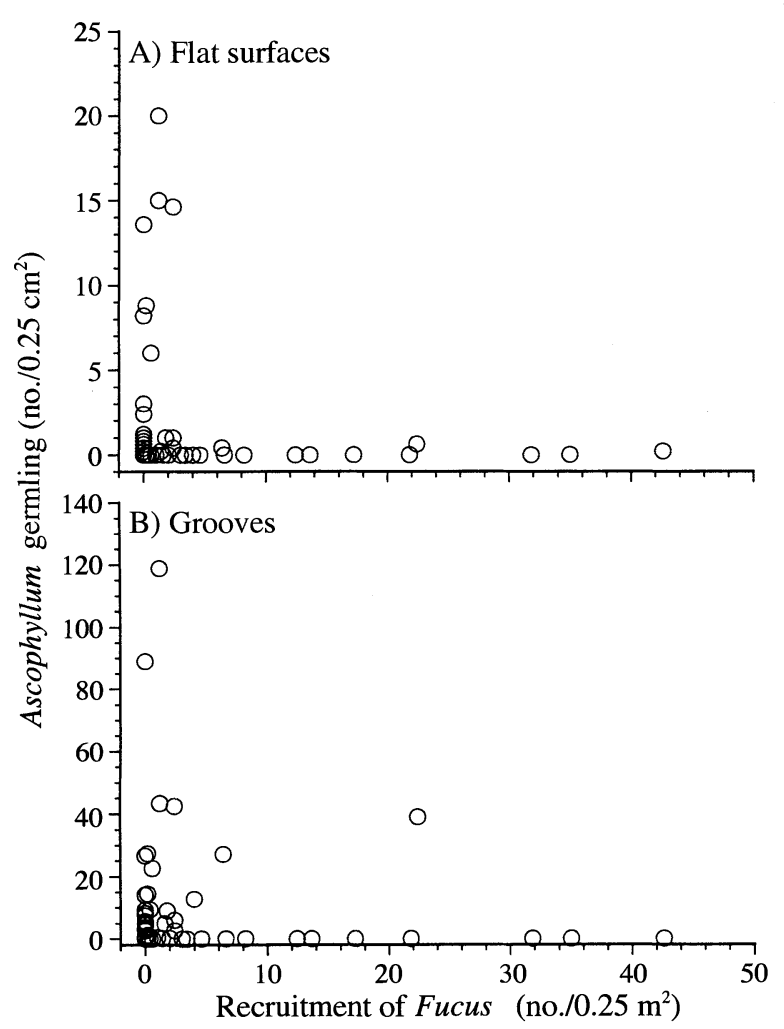

FIG. 3. Recruitment of Ascophyllum nodosum (A) on flat surfaces and (B) in grooves of tiles in April and May 1997 contrasted with the spring/summer recruitment on rock of Fucus spp. counted in August 1997 in the very same plot. Each symbol represents one of the 60 experimental plots.

was marginally nonsignificant (after Bonferroni adjustment at $5 \%$; $\alpha=0.013$ ), but again the power of this test was weak $(1-\beta<0.80)$. Either in or underneath pads, the patterns of recruitment with size of clearing did not vary in the different bays (Table 1).

The accumulation of sediment under the mussel recruitment pads showed no correlation with size of clearing (Kendall's $\tau=-0.137, P=0.19$ ). Neither was the recruitment of mussels in the pads nor mussels underneath pads correlated with sediment accumulation in a plot (mussels in pad, $300 \mu \mathrm{m}, \tau=0.029, P$ $=0.77 ; 425 \mu \mathrm{m}, \tau=0.017, P=0.87$; mussels underneath pads, $\tau=-0.078, P=0.45)$.

The recruitment of mussels in pads and underneath pads varied among sites within bays (Table 1). Estimates of the variance components indicate that most of the variability was associated with this factor (Table $1 ; 56.75 \%$ for $300 \mu \mathrm{m}$ and $53.21 \%$ for $425 \mu \mathrm{m}$ mussels, respectively, $38.56 \%$ for mussels underneath pads). As in the case of barnacles, data for mussels on rock underneath pads showed a pattern of less recruitment at the innermost site within the north-facing bays, but no apparent recruitment pattern in the two south-facing bays (Fig. 2). Recruitment of both size classes of mus-

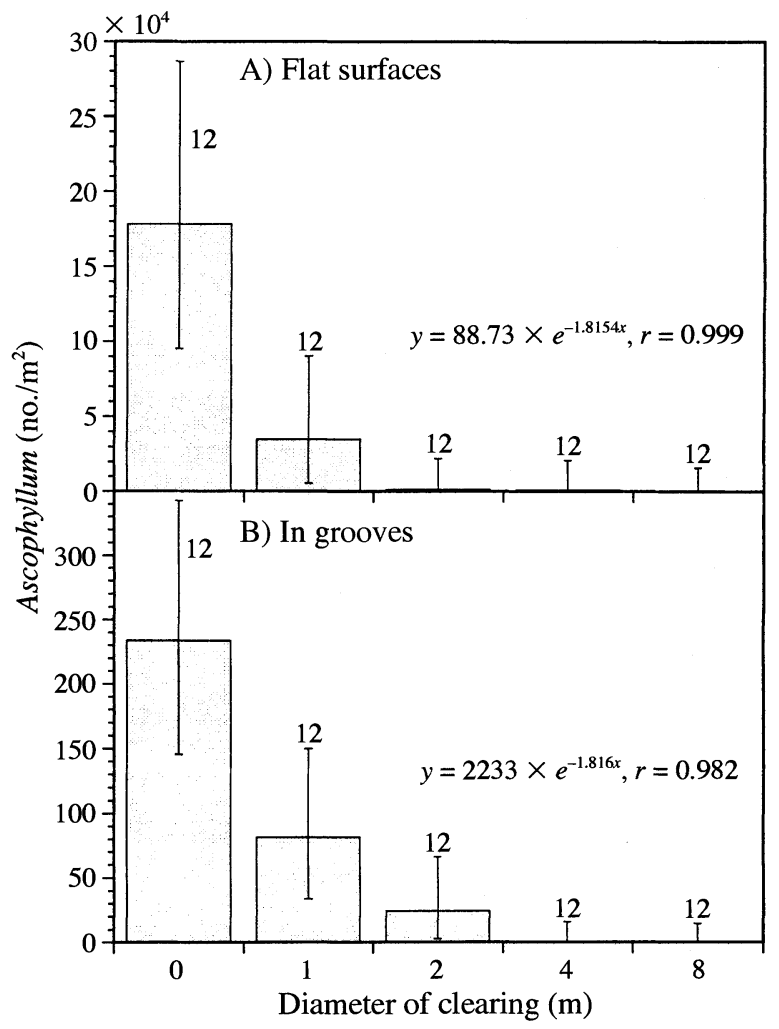

FIG. 4. Recruitment density of Ascophyllum nodosum (A) on flat surfaces and (B) in grooves of tiles in the differently sized experimental clearings. Data represent back-transformed means and $95 \%$ confidence intervals. Numbers above each column represent sample sizes. Equations describe the exponential decline in recruitment density with increased clearing size.

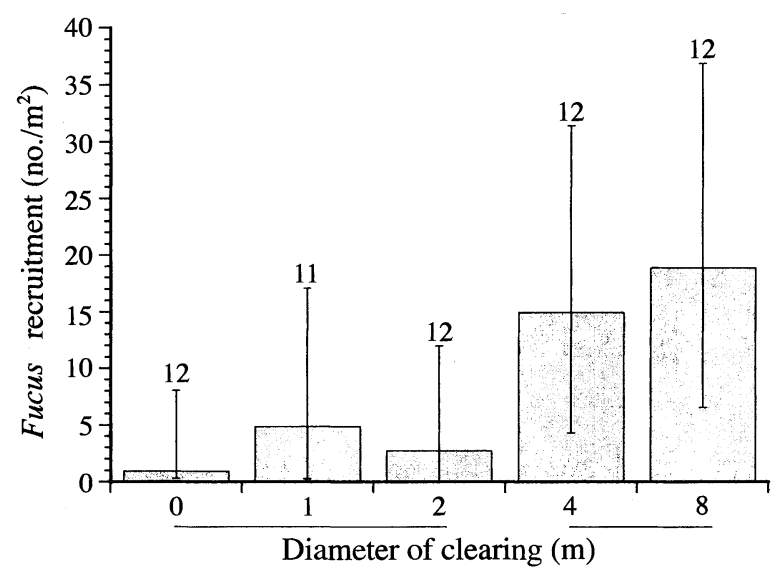

FIG. 5. Recruitment density of Fucus spp. in the differently sized experimental clearings. Data represent back-transformed means and $95 \%$ confidence intervals. Numbers above each column represent sample sizes. Breaks in the line under treatment levels indicate where significant step thresholds in recruitment occurred (based on planned contrasts at $\alpha=$ 0.0125 ; see Table 1 for significance of contrasts with and without suspected outlier). 

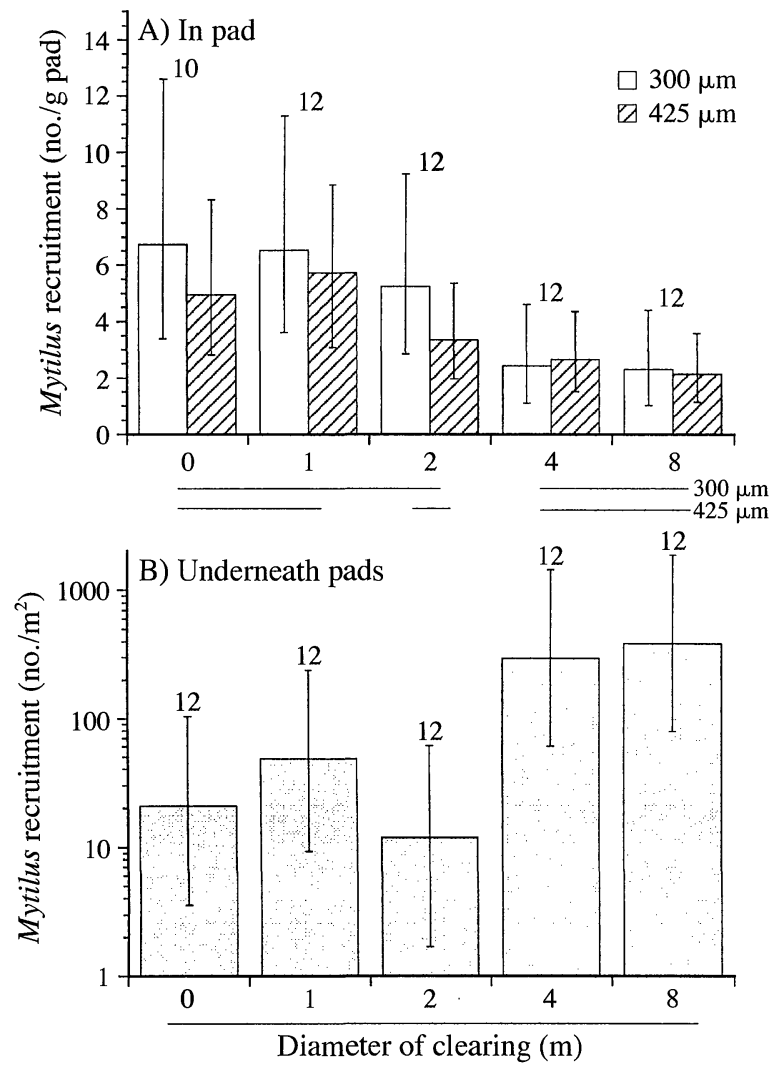

FIG. 6. Recruitment density of mussels (Mytilus edulis) (A) in the pads in the differently sized experimental clearings and (B) on rock underneath pads. Separate counts for mussels $300-425 \mu \mathrm{m}$ in size (open bars) or $\geq 425 \mu \mathrm{m}$ (hatched bars) were made on mussels in pads. Data represent back-transformed means and $95 \%$ confidence intervals. Numbers above each column represent sample sizes. Breaks in the line under treatment levels indicate where significant step thresholds in recruitment occurred (based on planned contrasts at $\alpha=$ $0.0125)$.

sels in pads, although site specific, showed no clear trend among sites within the four bays.

The recruitment of mussels did not differ overall among bays (Table 1). In contrast to barnacles, the recruitment of mussels tended to be greater in the northfacing rather than south-facing bays. However, like the analysis of barnacle data, the difference between northand south-facing bays was not significant (Table 1).

Recruitment of mussels on resin plates and of both size classes sieved from the pads was significantly correlated at $\alpha=0.05$ (Spearman rank correlations; resin plate vs. $425-\mu \mathrm{m}$ mussels from pads, $r=0.741$; resin plate vs. $300-\mu \mathrm{m}$ mussels from pads, $r=0.707$ ). At the site in Toothacher Cove, the recruitment density in pads of 300- and 425- $\mu \mathrm{m}$ mussels was 3.28 and 3.47 individuals $/ \mathrm{cm}^{2}$, respectively, and was approximately twelve fold that on plates $\left(0.28\right.$ individuals $\left./ \mathrm{cm}^{2}\right)$. At the Mackerel Cove site, recruitment densities were higher. Recruitment densities in pads for 300- and 425$\mu \mathrm{m}$ mussels was 17.70 and 17.39 individuals $/ \mathrm{cm}^{2}$, re- spectively, and that on plates was 3.44 individuals $/ \mathrm{cm}^{2}$ (approximately one-fifth that in pads). Across both sites the recruitment per square centimeter in pads was approximately eight to nine times greater than that on plates.

\section{DISCUSSION}

Our results indicate that the size of the clearing and the dispersal characteristics of propagules of each species were of overriding importance in determining the recruitment patterns in the mid-intertidal zone. In all four species the density of recruits varied with the size of the clearing. The specific pattern depended on whether the taxon was uncommon (i.e., barnacles, mussels, or Fucus) or common (i.e., Ascophyllum nodosum) in the surrounding community, which was dominated by Ascophyllum. Recruitment of barnacles and mussels, whose larvae disperse long distances, was strongly site specific probably due to current transport phenomena. Fucus vesiculosus, whose eggs disperse relatively short distances, also showed site specific recruitment, but that was because of local abundance of adult plants. In contrast, A. nodosum, whose eggs disperse short distances but was common at all sites, showed no significant variation among sites or bays.

\section{The size of clearing and subsequent recruitment}

As expected, A. nodosum recruited in large numbers to uncleared control plots and 1-m clearings, but few recruited to large clearings. In fact, recruitment densities declined exponentially with increasing clearing size. The same exponential rate of decline in recruitment that we observed on flat surfaces and in grooves of the tile suggest that grooves did not provide a refuge from mortality. The pattern suggests that $A$. nodosum is unlikely to recolonize very soon following relatively large scale clearings (here, $>2 \mathrm{~m}$ in diameter). Experiments testing dispersal distances and germling survival of A. nodosum suggest that post-settlement processes probably generate this pattern. The dispersal range of zygotes exceeds the sizes of our clearings ( $S$. R. Dudgeon, J. E. Kübler, W. Wright, R. L. Vadas, Sr., and P. S. Petraitis, unpublished manuscript), but germling mortality is extremely high within the first 3-4 mo (S. Dudgeon, unpublished data), and successful recruitment may be episodic (Vadas et al. 1990). If so, A. nodosum would not even close patches slowly over time by sexual recruits.

Well-known sources of fucoid germling mortality are desiccation and/or heat stress, water motion, grazing, and sweeping of canopy fronds (Vadas et al. 1992). Our experiment cannot distinguish among these sources, but desiccation and heat stress most likely kill many A. nodosum germlings in large clearings. We infer this because desiccation and heat stress in large clearings probably vary less across our sites than water motion and grazer densities, which is consistent with little variation in recruitment across clearing sizes in the dif- 
ferent bays. Germlings under canopies are usually protected from exposure during emersion, whereas those in 4- or 8-m clearings are always exposed. For example, a single such exposure often kills nearly $100 \%$ of 1 wk-old germlings of the fucoid Pelvetia fastigiata, whereas nearly $100 \%$ of $P$. fastigiata germlings outplanted at the same time underneath a canopy of adults survive (Brawley and Johnson 1991). Water motion may also be a factor. A. nodosum germlings are dislodged easily by water motion (Vadas et al. 1990), and to the extent that canopies of adult $A$. nodosum reduce flow rates, germling survival under canopies in small clearings also may be enhanced compared to that in large clearings. Sweeping of A. nodosum canopy fronds may kill many conspecific germlings, but presumably extremely heavy settlement underneath parents compensates for losses. Grazing may not influence the recruitment pattern of fucoids in clearings. Littorina littorea is by far the most abundant herbivore at our sites, is highly mobile, and densities during spring are no different among the differently sized clearings (P. S. Petraitis, E. Carlson, and S. R. Dudgeon, unpublished manuscript).

Unlike the pattern of $A$. nodosum, barnacles and the rockweed $F$. vesiculosus recruited in greater numbers to clearings $>2 \mathrm{~m}$ in diameter than to smaller clearings. In small clearings, the surrounding $A$. nodosum community may strongly affect the patch, whereas in large clearings the edge community has little effect. A. nodosum probably inhibits recruitment to small patches in two ways: (1) thalli impede access of propagules in the water column to the substrate, and (2) thalli moving in flow dislodge newly settled propagules. Canopy sweeping is probably a significant source of mortality of newly settled barnacle larvae and fucoid zygotes (as well as A. nodosum) as has been shown repeatedly with fucoid algae (Menge 1976, Vadas et al. 1992). The very largest individuals of $A$. nodosum at our sites approach $2 \mathrm{~m}$ in length, so sweeping is unlikely to kill propagules $\sim 2 \mathrm{~m}$ from the edge community (i.e., $\geq 4 \mathrm{~m}$ diameter clearings). The size of these thalli suggest that water motion at these sites is too low to break the fronds. We assume that the forces required to dislodge newly attached barnacle cyprids and Fucus are less than that required to break mature $A$. nodosum fronds. The forces on these young propagules may be sufficient to dislodge them even in slow flow if the mass of fronds acting on them is great.

In addition, canopies of $A$. nodosum also harbor predators of barnacles, including the gastropod Nucella lapillus and the green crab Carcinus maenas. N. lapillus consumes more mussels in small $(<2 \mathrm{~m}$ in diameter) compared to large clearings (Petraitis and Dudgeon 1999) and may prey on barnacle recruits in the differently sized clearings in a similar fashion. Data on barnacle mortality is consistent with this hypothesis ( $\mathrm{P}$. S. Petraitis, E. Carlson, and S. R. Dudgeon, unpublished manuscript). Thus, we suggest that mortality from canopy sweeping and predation decrease with an increase in the size of clearing and underlie the recruitment patterns of barnacles and $F$. vesiculosus.

Post-settlement processes affecting germlings of $A$. nodosum are the same as those affecting $F$. vesiculosus and barnacles, yet the recruitment patterns differ. What underlies the differences? We suspect that it reflects very different settlement patterns in the two cases. Whereas in A. nodosum many more zygotes settle underneath parents than further away (R. L. Vadas, Sr., and S. Dudgeon, unpublished data), access to available space in uncleared areas or small clearings for barnacle larvae and Fucus zygotes is probably impeded by the Ascophyllum canopy. Moreover, predation on barnacles may be scale dependent, but grazing of algal germlings by Littorina littorea appears not to be.

Recruitment of Mytilus edulis to pads was greater in small than in large clearings and was punctuated by two step-like transitions. The first occurred between the 1 and $2 \mathrm{~m}$ diameter clearings and the second occurred between the 2 and $4 \mathrm{~m}$ diameter clearings. Both size classes of recruits $(300-425 \mu \mathrm{m}$ and $>425 \mu \mathrm{m})$ appeared to exhibit this pattern, however, in the smaller size class, the first step is not well supported statistically. The concordant patterns of the two size classes suggests that the larger mussels are older (i.e., recruited earlier in the summer). Comparisons of recruitment on plates between years (this study and those reported in Petraitis 1991) at two sites indicate that recruitment in 1997 was well within the range reported for five previous years (1984-1988).

Greater recruitment of mussels in small clearings was contrary to the expected pattern. We expected greater recruitment in large clearings because of lower rates of predation on settlers, as occurs in the case of adult mussels (see Petraitis and Dudgeon 1999) and the lack of dislodgement by canopy sweeping. Instead, the observed pattern suggests greater settlement of mussels and/or enhanced survivorship in uncleared areas and small clearings compared to that in large clearings. This result is probably part real and part artifact of using pads. On one hand, greater settlement in habitats with algae (i.e., uncleared areas or small clearings) is consistent with the known settlement behavior of $M$. edulis. Mussels recruit to habitats via two settlement events: primary and secondary settlement (Bayne 1964). In the primary event, larvae settling from the water column to the benthos are attracted to algal turfs and often densely settle in and around algal stands (Bayne 1964). In secondary settlement, juvenile mussels relocate from the initial site to another site. Fibrous pads may enhance settlement by mimicking algal turfs and, given the sizes of these mussels $(\sim 300-425 \mu \mathrm{m})$, these data probably represent primary recruitment. Moreover, mortality rates of recruits may be lower in uncleared areas compared to that in clearings because of protection from dehydration and thermal stress during emersion by the overlying algal canopy (Petraitis and Dud- 
geon 1999). On the other hand, recruits in the pads probably were protected from dislodgement by canopy sweeping and predators more than were recruits to a rock surface. Pads may mimic important cues that enhance larval settlement of mussels, but they may also artificially reduce post-settlement mortality of recruits compared to that on rock. The recruitment of mussels on pads vs. plates that mimic a barnacle-covered rock surface is consistent with this hypothesis: recruitment per square centimeter on pads was on average eight to nine times that on the adjacent paired plate.

In contrast to pads, mussel recruits on the rock underneath the pads were marginally, but not significantly, more abundant in large $\left(>290 \mathrm{~m}^{2}\right)$ than in small clearings $\left(<50 \mathrm{~m}^{2}\right)$. These recruits, easily counted in situ with a hand lens, tended to be larger $(>500 \mu \mathrm{m})$ than those in pads and may represent secondary settlers that moved down through the pad and attached to rock. We acknowledge that these data contain artifacts in the context of interpretation as mussels on rock (the best test for our hypothesis) as they are recruits to rock with an overlying pad to protect them from predation, exposure, and canopy sweeping. However, we feel this interpretation is a conservative one in the context of our hypothesis for the following reasons: (1) the artifact of the overlying pad is to reduce mortality due to canopy sweeping and predation more in small clearings than in large ones, and (2) although pads protect recruits in clearings from exposure, mortality due to exposure is the same in clearings of all sizes (see Petraitis and Dudgeon 1999). Removing these artifacts presumably would provide stronger support for our hypothesized pattern of greater mussel recruitment in large clearings.

The difference in recruitment onto pads vs. rock surfaces bears further attention in the context of scaledependent recruitment and community divergence. If the data from pads and underneath pads reflect primary and secondary recruitment patterns, respectively, at all, the contrast between them is illuminating. In either case, mussel recruitment appears to depend on spatial scale, but for different reasons. Greater recruitment to pads in uncleared areas and small clearings may reflect settlement preference for algal-dominated habitats over clearings. If recruitment to natural rock surfaces is indeed greater in large clearings, then it suggests that either (or both) migration or scale-dependent mortality during secondary settlement annihilate the primary settlement pattern. In order for a divergent community of mussels to develop scale-dependent mortality that favors individuals in large clearings must prevail.

Neither the recruitment of mussels in pads or underneath pads was correlated with sediment accumulation in plots. Moreover, no correlation was evident between sediment accumulation and clearing size. Whatever hydrodynamic changes occurred following canopy removal they were insufficient to differentially affect sedimentation and hence, mussel recruitment, in the differently sized clearings.

\section{Dispersal potential and site-specific recruitment}

The contrasting recruitment patterns of the two fucoid algae merits further attention in the context of their dispersal capabilities. Dispersal of fucoid zygotes typically shows a negative exponential function. Because of this, we expected that recruitment of A. nodosum would vary with spatial scale. Indeed, recruitment of A. nodosum in clearings reflects such a pattern, though it declines more steeply than the dispersal shadow ( $S$. R. Dudgeon, J. E. Kübler, W. Wright, R. L. Vadas, Sr., and P. S. Petraitis, unpublished manuscript) implying heavy post-settlement mortality in clearings. We did not expect recruitment to vary among sites because we chose sites in which $A$. nodosum was very abundant, and recruitment of $A$. nodosum did not vary among sites within bays, which is consistent with local limited dispersal of zygotes.

Recruitment of $F$. vesiculosus, on the other hand, varied significantly from site to site, and the pattern of recruitment in clearings bears no relation to a typical dispersal shadow. These results, however, are not surprising given that (1) we did not control for the abundance of $F$. vesiculosus at the different sites, (2) we do not know the source thalli of recruited zygotes, and (3) differential post-settlement mortality across clearing sizes could blur the initial pattern of dispersal. One observation suggests source populations could be extremely important for Fucus recruitment. The single outlier, which was anomalously high, coincided with a nearby dense patch of adult thalli.

Recruitment of both Semibalanus balanoides and $M$. edulis was strongly site specific. We did not expect site-specific recruitment of barnacles and mussels because both have pelagic larvae that spend several weeks in the plankton and disperse widely, and recruitment is often unrelated to local abundance (e.g., Gaines and Roughgarden 1985). Nevertheless, our finding of site specificity is not too surprising since recruitment of barnacles and mussels elsewhere has been shown to be site specific (Caffey 1985, Raimondi 1990, Petraitis 1991).

More interesting is the possibility that recruitment of barnacles and mussels on Swans Island may differ among sites due to their relative location within bays. Such variation has been documented elsewhere (Southward and Crisp 1956, Kautsky 1982, Caffey 1985, Gaines and Roughgarden 1985). Our data suggest barnacle and mussel recruitment in the two north-facing bays was less at the innermost sites than at sites nearer the mouth. This may reflect either less larval settlement, higher early post-settlement mortality, or both at sites further back in bays. In contrast, no clear trend in recruitment was evident for either species within south-facing bays. We suspect that the recruitment differences between north- and south-facing bays and 
among sites within bays reflect differences in larval flux associated with transport phenomena since similar cases have been reported elsewhere (Gaines and Bertness 1993, Leonard et al. 1998).

The large variance components for residuals suggests that in addition to variation in recruitment among sites within bays, variable recruitment may occur on the smaller spatial scale within sites as well (e.g., for barnacles, the error variance component $=70.8 \%$ which reflects variation on the scale of $\sim 75-100 \mathrm{~m}$ ). For example, at one site (Dick's) the two western most plots had the highest barnacle recruitment (231 and 132 recruits per plate, respectively, from west to east), whereas the three remaining plots to the east were recessed in a small cove and had few recruits $(1,6$, and 26 recruits per plate, respectively, from west to east). Again, this may reflect variation in larval flux (Gaines and Bertness 1993, Leonard et al. 1998), but on a smaller spatial scale.

\section{Implications for community development}

Succession on rocky shores in the northwest Atlantic commences most often during spring following severe winter storms or ice scour events (e.g., Mathieson et al. 1982, Wethey 1985, Witman 1987, McCook and Chapman 1991). At our sites on sheltered shores in the Gulf of Maine, ice scour events that clear space probably occur infrequently as suggested by the size and persistence of rockweed stands. Nevertheless, when they occur, barnacles, which recruit from March through May, are among the earliest colonizers of clearings. Barnacles may play a pivotal role during succession because they facilitate recruitment of each of the three foundation species (A. nodosum, F. vesiculosus, and $M$. edulis) that can potentially dominate a clearing late in succession (Menge 1976, Petraitis 1987, 1990; R. L. Vadas, Sr., unpublished data). Thus, clearings on sheltered shores may be colonized early by barnacles, but could later be occupied either by communities dominated by A. nodosum, $F$. vesiculosus, or M. edulis.

Our experiment investigating recruitment into clearings within $A$. nodosum stands by barnacles and each potential dominant species shows that (1) clearing size affects subsequent patterns of recruitment, (2) the respective scale-dependent recruitment pattern of each species did not differ significantly from bay to bay, and (3) recruitment of barnacles, F. vesiculosus, and mussels varied site specifically. These results have two implications for the development of communities on sheltered rocky shores in New England. First, the starting point and initial trajectory of succession is contingent upon the size of the clearing. Thus, in large clearings A. nodosum does poorly, but barnacles, mussels, and F. vesiculosus do well. Second, site-specific variation in recruitment implies that the rate of succession varies from place to place.

Succession, however, is not strictly a function of the recruitment imprint in clearings. Post-settlement pro- cesses reinforce the recruitment pattern in the case of barnacles and override the recruitment pattern in the case of mussels. Predation pressure is high on barnacles and mussels by Nucella lapillus and Carcinus maenas underneath $A$. nodosum canopies or in small clearings, but low in large clearings (Leonard et al. 1998, Petraitis and Dudgeon 1999; P. S. Petraitis, E. Carlson, and S. R. Dudgeon, unpublished manuscript).

Small clearings ( $\leq 2 \mathrm{~m}$ ) will likely revert to an $A$. nodosum canopy. In these clearings, few barnacles or F. vesiculosus recruit, although some mussels do. Few of any of these species have persisted in these clearings. In small clearings recruitment of $A$. nodosum is greater and mortality rates of germlings are lower than in large clearings (S. Dudgeon, unpublished data). The convergence of these small clearings towards the surrounding community is consistent with successional trajectories of small patches studied elsewhere (Paine and Levin 1981, Sousa 1984, Berlow 1997, Chapman and Underwood 1998).

By contrast, the dynamics of large clearings (4 and $8 \mathrm{~m}$ diameter) are less predictable. We suggest that they may continue diverging from the surrounding $A$. nodosum community. Two alternative assemblages seem likely; one dominated by barnacles and mussels or one dominated by $F$. vesiculosus. Barnacles, mussels, and $F$. vesiculosus all recruit and survive well thereafter in large clearings within A. nodosum stands (Petraitis and Dudgeon 1999; P. S. Petraitis, E. Carlson, and S. R. Dudgeon, unpublished manuscript). Once established, each of these assemblages usually persists. Indeed, some of our large clearings already have been taken over by $F$. vesiculosus and barnacles, and the densities of mussels are increasing in others.

Although possible, it seems unlikely that large clearings will converge towards the surrounding A. nodosum community for several reasons. First, there is no clear evidence showing that any of these late successional stages can be replaced by the others through competition (McCook and Chapman 1991, 1993). Thus, earlier establishment of either of the other two assemblages should inhibit colonization by A. nodosum, necessitating further disturbance. Second, successful recruitment of $A$. nodosum appears episodic (Vadas et al. 1990). Third, survival of $A$. nodosum germlings in large clearings is poor ( $\mathrm{S}$. Dudgeon, unpublished data).

The dispersal and recruitment characteristics of these species, particularly the short distances that $A$. nodosum recruits, begs the question of what keeps Ascophyllum communities from local extinction and mussels or Fucus from dominating at all sites. We suggest, as have others (e.g., Åberg 1992), that A. nodosum has great longevity. Disturbances large enough to cause a switch from $A$. nodosum to another assemblage are very rare, but they do occur. These instances of rare disturbances with a high probability of a switch from $A s$ cophyllum are balanced by frequent disturbances of sufficient magnitude to mussel and Fucus beds, but a 
very low probability per event of a switch to Ascophyllum. A. nodosum can disperse long distances via rafting of detached, fertile fronds (e.g., from ice scour). Free-floating rafts of fertile fronds are common. Moreover, those that are deposited on mussels in the intertidal zone often become attached by the mussel's byssal threads and release gametes (S. Dudgeon, personal observation). This may be the mechanism by which new A. nodosum communities arise.

Our data imply that a single site may switch from an Ascophyllum stand to another assemblage at a critical clearing size. As such, it suggests evidence for mechanisms underlying the origin of alternative rockweed or barnacle-mussel communities on sheltered rocky shores (Petraitis and Latham 1999). Theory predicts that transitions between alternative states occur at critical thresholds (Noy-Meir 1975, May 1977, Knowlton 1992). Most of our experimental evidence is consistent with theoretical predictions. Patterns of both recruitment (for barnacles and Fucus) and postrecruitment mortality (for mussels and barnacles; Petraitis and Dudgeon 1999; P. S. Petraitis, E. Carlson, and S. R. Dudgeon, unpublished manuscript) show threshold responses at a critical clearing size of $\sim 4 \mathrm{~m}$ in diameter.

Our data address the issue of the origin of alternative states, but they say nothing about the maintenance, or stability, of those states (see Connell and Sousa 1983, Sousa and Connell 1985). We know of no experimental data that has tested the stability of any of these assemblages in any habitat. However, the resilience of $M y$ tilus (Lubchenco and Menge 1978) and Fucus (Minchinton et al. 1997) communities to storms and/or sea ice and Ascophyllum to ice damage (Mathieson et al. 1982, Åberg 1992) suggests it is a plausible hypothesis worthy of testing. In addition to experiments demonstrating the stability of these three communities to perturbations, evidence showing that rockweeds can become established and persist in former mussel beds is needed to demonstrate that these assemblages represent alternative states rather than successional features of communities driven by site-specific differences. Experiments testing these hypotheses are in progress.

Both rockweeds and mussels live in a broad range of intertidal habitats. Exposed sites, where barnaclemussel beds often dominate, are not suitable environments for A. nodosum (Vadas et al. 1990). Conversely, barnacle-mussel beds may not successfully establish themselves at estuarine sites where $A$. nodosum predominates (Leonard et al. 1998). At some sheltered sites, either assemblage, or one dominated by $F$. vesiculosus, may persist, but which one appears contingent upon history at each site. The fact that sheltered sites are suitable for any of three assemblages, but is only a subset of the broader range of environments occupied by each, blinds us from recognizing alternative states in environments where they may, in fact, exist. This added complexity makes the detection of alternative states even more challenging, but no less critical.

ACKNOWLEDGMENTS

We thank Emma Trask, Dana Henry, Carol Petraitis, and Daniel Petraitis for help with removing $20000 \mathrm{~kg}$ of Ascophyllum and Erika Carlson for help collecting data in the field and laboratory. We are grateful for the support of this research by the residents of Swans Island, Maine and especially thank John and Carolyn Grace, John and Marilyn MacDuffie, Joy MacDonald, Bob Horton, George Scott, and Dick Jellison for providing access to the shore across their properties. S. Dudgeon thanks J. Kübler for her support during this project. S. Gaines, J. Witman, M. Bertness, and an anonymous reviewer provided insightful comments on earlier versions of this manuscript. This research was supported by National Science Foundation grant (OCE 95-29564) to P. S. Petraitis.

\section{Literature Cited}

Åberg, P. 1992. A demographic study of two populations of the seaweed Ascophyllum nodosum. Ecology 73:14731487.

Bacon, L., and R. L. Vadas. 1991. A model for gamete release in Ascophyllum nodosum (Phaeophyta). Journal of Phycology 27:166-173.

Bayne, B. L. 1964. Primary and secondary settlement in Mytilus edulis L. (Mollusca). Journal of Animal Ecology 33: 513-523.

Bedford Institute of Oceanography. 1987. State of the ocean: March. Weekly briefing 24 April 1987. Bedford Institute of Oceanography, Bedford, Nova Scotia, Canada.

Bergeron, P., and E. Bourget. 1984. The effect of cold temperatures and ice on intertidal populations in northern regions, particularly in the St. Lawrence estuary. Oceanis 10: 259-278.

Berlow, E. L. 1997. From canalization to contingency: historical effects in a successional rocky intertidal community. Ecological Monographs 67:435-460.

Bertness, M. D., and R. Callaway. 1994. Positive interactions in communities. Trends in Ecology and Evolution 9:191193.

Bethel, L. J. 1973. Spawning and settlement of Mytilus edulis L. Dissertation. University of Pennsylvania, Philadelphia, Pennsylvania, USA.

Brawley, S. H., and L. E. Johnson. 1991. Survival of fucoid embryos in the intertidal zone depends on developmental stage and microhabitat. Journal of Phycology 27:179-186.

Butler, A. J. 1991. Effect of patch size on communities of sessile invertebrates in Gulf St. Vincent, South Australia. Journal of Experimental Marine Biology and Ecology 153: 255-280.

Caffey, H. M. 1985. Spatial and temporal variation in settlement and recruitment of intertidal barnacles. Ecological Monographs 55:313-332.

Caley, M. J., M. H. Carr, M. A. Hixon, T. P. Hughes, G. P. Jones, and B. A. Menge. 1996. Recruitment and the dynamics of open marine populations. Annual Review of Ecology and Systematics 27:477-500.

Cervin, G., and P. Åberg. 1997. Do Littorina spp. affect the survival of Ascophyllum nodosum germlings? Journal of Experimental Marine Biology and Ecology 218:35-47.

Chapman, M. G., and A. J. Underwood. 1998. Inconsistency and variation in the development of rocky intertidal algal assemblages. Journal of Experimental Marine Biology and Ecology 224:265-289.

Connell, J. H., T. P. Hughes, and C. C. Wallace. 1997. A 30year study of coral abundance, recruitment, and disturbance at several scales in space and time. Ecological Monographs 67:461-488

Connell, J. H., and W. P. Sousa. 1983. On the evidence needed 
to judge ecological stability or persistence. American Naturalist 121:789-824.

Dayton, P. K. 1972. Toward an understanding of community resilience and the potential effects of enrichments to the benthos at McMurdo Sound, Antarctica. Pages 81-95 in B. C. Parker, editor. Proceedings of the Colloquium on Conservation Problems in Antarctica, Allen Press, Lawrence, Kansas, USA.

Drake, J. A., T. E. Flum, G. J. Witteman, T. Voskuil, A. M. Hoylman, C. Creson, D. A. Kenny, G. R. Huxel, C. S. Larue, and J. R. Duncan. 1993. The construction and assembly of an ecological landscape. Journal of Animal Ecology 62:117-130.

Elner, R. W., and R. L. Vadas. 1990. Inference in ecology: the sea urchin phenomenon in the north-west Atlantic. American Naturalist 136:108-125.

Fritsch, F. E. 1945. The structure and reproduction of the algae. Volume II. Cambridge University Press, Cambridge, UK.

Gaines, S. D., and M. D. Bertness. 1993. Measuring juvenile dispersal: why field ecologists must learn to integrate. Ecology 74:2430-2435.

Gaines, S. D., and J. Roughgarden. 1985. Larval settlement rate: a leading determinant of structure in an ecological community of the marine intertidal zone. Proceedings of the National Academy of Sciences, USA 82:3707-3711.

Hatcher, B. G. 1984. A maritime accident provides evidence for alternate stable states in benthic communities on coral reefs. Coral Reefs 3:199-204.

Jones, C. G., J. H. Lawton, and M. Shachak. 1994. Organisms as ecosystem engineers. Oikos 69:373-386.

Kautsky, N. 1982. Quantitative studies on gonad cycle, fecundity, reproductive output and recruitment in a Baltic Mytilus edulis population. Marine Biology 68:143-160.

Keough, M. J. 1984. Effects of patch size on the abundance of sessile marine invertebrates. Ecology 65:423-437.

Kim, J. H., and R. E. DeWreede. 1996. Effects of size and season of disturbance on algal patch recovery in a rocky intertidal community. Marine Ecology Progress Series 133: 217-228.

$\rightarrow$ Knowlton, N. 1992. Thresholds and multiple stable states in coral reef community dynamics. American Zoologist 32: 674-682.

Lazo, L., J. H. Markham, and A. R. O. Chapman. 1994. Herbivory and harvesting: effects on sexual recruitment and vegetative modules of Ascophyllum nodosum. Ophelia 40: 95-113.

Leonard, G. H., J. M. Levine, P. R. Schmidt, and M. D. Bertness. 1998. Flow-driven variation in intertidal community structure in a Maine estuary. Ecology 79:13951411.

Levin, S. A., and R. T. Paine. 1974. Disturbance, patch formation and community structure. Proceedings of the National Academy of Sciences, USA 71:2744-2747.

Lewis, J. R. 1964. The ecology of rocky shores. English University Press, London, UK.

Lewontin, R. C. 1969. The meaning of stability. Brookhaven Symposium in Biology 22:13-24.

Lubchenco, J., and B. A. Menge. 1978. Community development and persistence in a low rocky intertidal zone. Ecological Monographs 59:67-94.

Markham, W. E. 1980. Ice atlas: eastern Canadian seaboard. Canadian Government Publishing Centre, Hull, Quebec, Canada.

Mathieson, A. C., C. A. Penniman, P. K. Busse, and E. TveterGallagher. 1982. Effects of ice on Ascophyllum nodosum within the Great Bay estuary system of New HampshireMaine. Journal of Phycology 18:331-336.

May, R. 1977. Thresholds and breakpoints in ecosystems with a multiplicity of stable states. Nature 269:471-477.
McCook, L. J. 1992. Species interactions and community structure during succession following massive ice scour of a rocky intertidal seashore. Dissertation. Dalhousie University, Halifax, Nova Scotia, Canada.

McCook, L. J., and A. R. O. Chapman. 1991. Community succession following massive ice-scour on an exposed rocky shore: effects of Fucus canopy algae and of mussels during late succession. Journal of Experimental Marine Biology and Ecology 154:137-169.

McCook, L. J., and A. R. O. Chapman. 1993. Community succession following massive ice-scour on an exposed rocky shore: recruitment, competition and predation during early, primary succession. Marine Biology 115:565-575.

Menge, B. A. 1976. Organization of the New England rocky intertidal community: role of predation, competition, and environmental heterogeneity. Ecological Monographs 46: 355-393.

Minchinton, T. E., R. E. Scheibling, and H. L. Hunt. 1997. Recovery of an intertidal assemblage following a rare occurrence of scouring by sea ice in Nova Scotia, Canada. Botanica Marina 40:139-148.

Noy-Meir, I. 1975. Stability of grazing systems: an application of predator-prey graphs. Journal of Ecology 63:459481.

Paine, R. T., and S. A. Levin. 1981. Intertidal landscapes: disturbance and the dynamics of pattern. Ecological Monographs 51:145-178.

Peterman, R. 1990. Statistical power analysis can improve fisheries research and management. Canadian Journal of Fisheries and Aquatic Science 47:2-15.

Peterson, C. H. 1984. Does a rigorous criterion for environmental identity preclude the existence of multiple stable points? American Naturalist 124:127-133.

Petraitis, P. S. 1987. Factors organizing rocky intertidal communities of New England: herbivory and predation in sheltered bays. Journal of Experimental Marine Biology and Ecology 109:117-136.

Petraitis, P. S. 1990. Direct and indirect effects of predation, herbivory and surface rugosity on mussel recruitment. Oecologia 83:405-413.

Petraitis, P. S. 1991. Recruitment of the mussel Mytilus edulis L. on sheltered and exposed shores in Maine, U.S.A. Journal of Experimental Marine Biology and Ecology 147:6580.

Petraitis, P. S., and S. R. Dudgeon. 1999. Experimental evidence for the origin of alternative communities on rocky intertidal shores. Oikos 84:239-245.

Petraitis, P. S., and R. E. Latham. 1999. The importance of scale in testing the origins of alternative community states. Ecology 80:429-442.

Phillips, D. L., and D. J. Shure. 1990. Patch-size effects on early succession in southern Appalachian forests. Ecology 71:204-212.

Pickett, S. T. A., and P. S. White. 1985. The ecology of natural disturbance and patch dynamics. Academic Press, Orlando, Florida, USA.

Raimondi, P. T. 1990. Patterns, mechanisms, consequences of variability in settlement and recruitment of an intertidal barnacle. Ecological Monographs 60:283-309.

Reynolds, N. 1969. The settlement and survival of young mussels in the Conway fishery. Ministry of Agriculture, Fisheries and Food, Fishery Investigations, Series II 26:111 .

Ricklefs, R. E. 1987. Community diversity: relative roles of local and regional processes. Science 235:167-171.

Samuels, C. L., and J. A. Drake. 1997. Divergent perspectives on community convergence. Trends in Ecology and Evolution 12:427-432.

SAS Institute. 1989. SAS/STAT user's guide. Version 6. Vol- 
ume 2. Fourth edition. SAS Institute, Cary, North Carolina, USA.

Shumway, S., and M. D. Bertness. 1994. Patch size effects on marsh plant secondary succession mechanisms. Ecology 75:564-568.

Simenstead, C. A., J. A. Estes, and K. W. Kenyon. 1978. Aleuts, sea otters, and alternative stable state communities. Science 200:403-411.

Sokal, R. R., and F. J. Rohlf. 1995. Biometry. Third edition. W. H. Freeman, San Francisco, California, USA.

Sousa, W. P. 1984. The role of disturbance in natural communities. Annual Review of Ecology and Systematics 15: 363-391.

Sousa, W. P., and J. H. Connell. 1985. Further comments on the evidence for multiple stable points in natural communities. American Naturalist 125:612-615.

Southward, A. J., and D. J. Crisp. 1956. Fluctuations in the distribution and abundance of intertidal barnacles. Journal of the Marine Biological Association of the United Kingdom 35:211-229.

Sutherland, J. P. 1974. Multiple stable points in natural communities. American Naturalist 108:859-873.
Sutherland, J. P. 1981. The fouling community at Beaufort, North Carolina: a study in stability. American Naturalist 118:499-519.

Tanner, J. E., T. P. Hughes, and J. H. Connell. 1996. The role of history in community dynamics: a modelling approach. Ecology 77:108-117.

Vadas, R. L., and R. W. Elner. 1992. Plant-animal interactions in the north-west Atlantic. Pages 33-60 in D. M. John, S. J. Hawkins, and J. H. Price, editors. Plant-animal interactions in the marine benthos. Systematics Association Special Volume 46. Clarendon, Oxford, UK.

Vadas, R. L., S. Johnson, and T. A. Norton. 1992. Recruitment and mortality of early post-settlement stages of benthic algae. British Phycological Journal 27:331-351.

Vadas, R. L., W. Wright, and S. L. Miller. 1990. Recruitment of Ascophyllum nodosum: wave action as a source of mortality. Marine Ecology Progress Series 61:263-272.

Wethey, D. S. 1985. Catastrophe, extinction, and species diversity: a rocky intertidal example. Ecology 66:445-456.

Witman, J. 1987. Subtidal coexistence: storms, grazing, mutualism, and the zonation of kelps and mussels. Ecological Monographs 57:167-187. 